\title{
Development of Portable Rehabilitation Device Using Flexible-Extension- Type Soft Actuator with Built-In Small-Sized Quasi-Servo Valve and Displacement Sensor ${ }^{*}$
}

\author{
So SHIMOOKA ${ }^{* *}$, Shujiro DOHTA ${ }^{* *}$, Tetsuya AKAGI ${ }^{* *}$, Wataru KOBAYASHI ${ }^{* *}$ \\ and Masataka YONEDA**
}

\begin{abstract}
Welfare pneumatic equipments to support nursing care and rehabilitation for the elderly and the disabled are being actively studied and developed. The total weight of a wearable device increases according to the degree of freedom of the device. In this study, a low-cost extension-type soft actuator with a longer displacement was proposed and tested. A maximum displacement of $270 \mathrm{~mm}$ (235\%) could be obtained. By using the actuator, a disposable flexible robot arm was developed. As a result, we confirmed that the robot arm is able to extend straight and bend in any direction. An analytical model of the arm is proposed to predict the attitude of the arm. To control the actuator, a flow rate control-type quasi-servo valve with a built-in driving circuit using an embedded controller is also proposed and tested. In addition, a portable rehabilitation device using the low-cost robot arm with disposable displacement sensors, and three quasi-servo valves is developed.
\end{abstract}

Keywords: Extension-type actuator, Built-in quasi-servo valve, Rehabilitation device, Wire-type liner potentiometer

\section{Introduction}

Currently, welfare pneumatic equipments to support nursing care and rehabilitation for the elderly and the disabled are being actively researched and developed by many researchers ${ }^{1-4)}$. The purpose of our study is to develop a home rehabilitation device that includes a controller, valves, sensors, and pneumatic actuator. The total weight of a wearable device increases according to the degree of freedom of the device. Therefore, to decrease the burden of the user, light-weight pneumatic soft actuators are used. Because, the actuator has relatively larger ratio of generated force to mass and compliance based on air compressibility. A small-sized and lightweight pressure-control-type quasi-servo valve was also developed in our previous study ${ }^{5)-6}$. We also developed portable rehabilitation device using flexible spherical actuator that can provide passive exercise for the upper limb by changing the position of holding hands ${ }^{7}$. However, the actuator only gives position change on spherical surface. It is impossible to change the distance between both hands. Therefore, the device that can give the extension/contraction and bending motion is required. To realize such a device with a compact configuration, it is necessary to develop an extension-type soft actuator with a longer stroke. As Such an actuator, Noritsugu ${ }^{8)}$ developed the extension type rubber

\footnotetext{
* Manuscript received April 23, 2018

** Okayama University of Science

(1-1 Ridai-cho, Kita-ku, Okayama, Japan)

E-mail: t17sd01ss@ous.jp
}

artificial muscle. Elliot Hawkes ${ }^{9)}$ also developed the 300\% strain soft artificial muscle. In this paper, we propose and test a low-cost flexible-extension-type soft actuator that it can be easily constructed by using the water supply tube on the market. Because, the desired rehabilitation device is only used for short period to recover their physical ability. After therapy, in order to reuse it, it needs much cost to wash moving parts in the device. Therefore, as taking account of cost burden for user, the low-cost actuator unit that can be disposable after using it is required.

Based on the concept, we aim to develop a low-cost flexible robot arm using extension-type soft actuators with displacement sensor. We also consider that the device can be divided into the control unit with integrated valves and the actuator unit with low cost sensors. In order to reuse the control unit, the flow rate control-type quasi-servo valve with a built-in embedded controller ${ }^{10)}$ and an attitude controller are proposed and tested.

As a built-in displacement sensor, we develop several types of flexible displacement sensors ${ }^{11-12)}$. As a disposable sensor in the actuator unit, a wire-type linear potentiometer ${ }^{13)}$ is used. Figure 1 shows a final target image of proposed portable rehabilitation device. As shown in Fig. 1, we aim to develop a portable rehabilitation device that provides force to the human arm and shoulder and acts as an active expander and bender. As first step of the development, a low-cost portable rehabilitation device for wrist that the actuator unit with sensor can be disposable is proposed and tested. In particular, 
the system integration of valve units, an attitude controller and the actuator unit with sensor is described. The construction and operating principle of the actuator unit, that is a flexible robot arm, are also described.

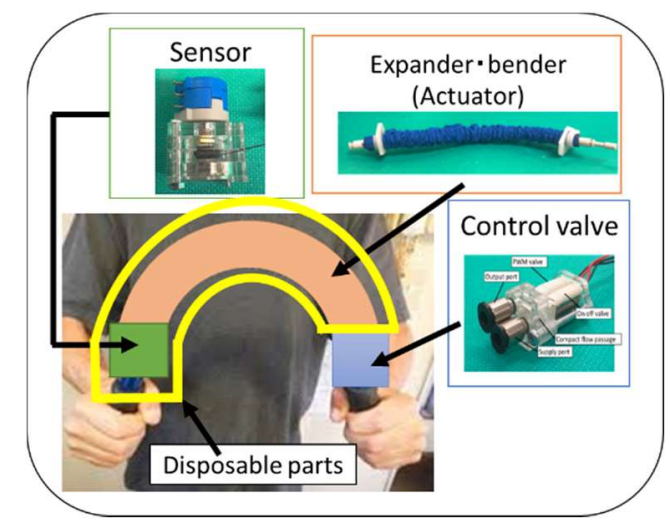

Fig. 1 Image of proposed portable rehabilitation device

\section{Nomenclature}

$\begin{array}{lll}A & : & \text { sectional area of the tube }\left[\mathrm{m}^{2}\right] \\ k & : & \text { elastic coefficient }[\mathrm{N} / \mathrm{m}] \\ L & : & \text { central length of the robot arm }[\mathrm{m}] \\ L_{0 i} & : & \text { initial length of each actuator }[\mathrm{m}] \\ L_{i} & : & \text { length of each actuator }[\mathrm{m}] \\ R & : & \text { radius of curvature of the robot arm }[\mathrm{m}] \\ r & : & \text { distance between the center of the arm } \\ & : & \text { and the center of each actuator }[\mathrm{m}] \\ P_{i} & : & \text { supply pressure }[\mathrm{Pa}] \\ P_{\min } & : & \text { minimum supply pressure }[\mathrm{Pa}] \\ \alpha & : & \text { bending direction angle }[\mathrm{rad}] \\ \beta & : & \text { bending angle }[\mathrm{rad}] \\ \text { Subscript } & & \\ i & : & \text { number of each actuator }\end{array}$

\section{Extension-Type Soft Actuator}

Figure 2 shows an external view and schematic diagram of the proposed extension-type soft actuator. The tested actuator consists of a rubber tube covered with a ruffled fabric sleeve. The ruffled fabric tube is used as an ordinal water supply tube (TAISHO INDUSTRY Co. Ltd., Magic hose). The fundamental concept of the tested actuator is almost same as Noritsugu and Elliot Hawkes's actuators ${ }^{8)-9)}$. The difference between both actuators and our actuator is a covered sleeve. Hawkes's actuator has the coil type covered sleeve. Noritsugu used the bellows type nylon mesh as a sleeve. Our actuator is similar to Noritsugu's actuator. Compared with these actuators, the material of our actuator can be easily obtained on the market. The cost of the tube for $1 \mathrm{~m}$ is cheap, that is about 6 US dollars. Comparing the strain of these actuators at the applied pressure of $400 \mathrm{kPa}$, Noritsugu's, Hawkes's and ours are $170 \%, 230 \%$, and $235 \%$, respectively. The rubber tube in the sleeve has an inner diameter of $6 \mathrm{~mm}$, outer diameter of $9.5 \mathrm{~mm}$, and length of $200 \mathrm{~mm}$. The original length of the ruffled fabric sleeve in the stretched condition is $450 \mathrm{~mm}$. Figure 3 shows the relation between the supply pressure and displacement of the actuator. In the experiment, the actuator was pressurized from 0 to $400 \mathrm{kPa}$ every $20 \mathrm{kPa}$ by using a pressure regulator.

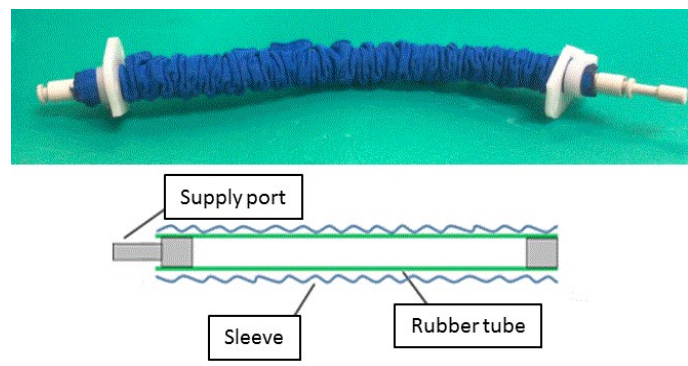

Fig. 2 External view and schematic diagram of tested extension-type soft actuator

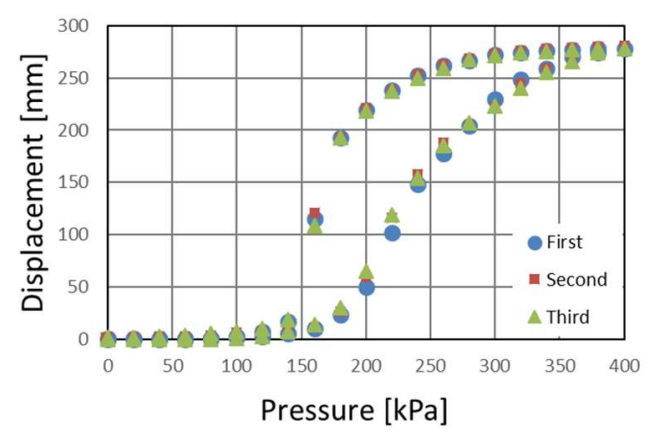

Fig. 3 Relation between supply pressure and displacement of the actuator

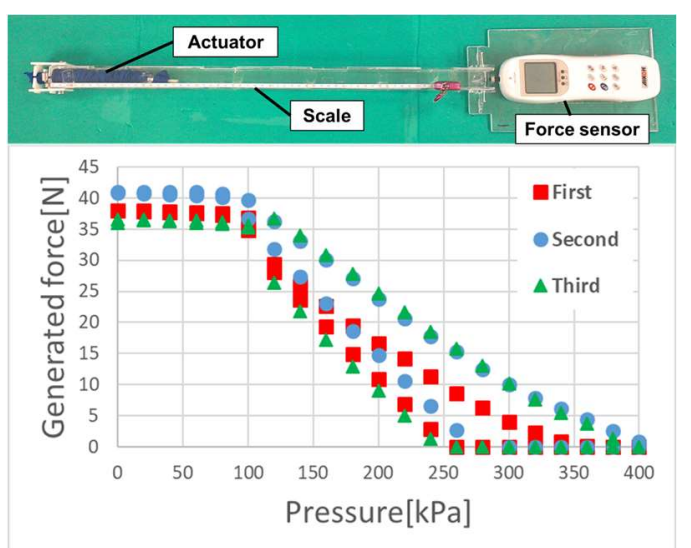

Fig. 4 Relation between supply pressure and generated force of the actuator 
Measurements were carried out a total of three times. The maximum displacement of the actuator of about $270 \mathrm{~mm}$, that is, a $235 \%$ extension of the original length, can be obtained when an input pressure of $400 \mathrm{kPa}$ is applied. It is also found that hysteresis caused by the friction between the tube and the sleeve can be observed. To reduce the hysteresis, it is necessary to execute a position feedback control using a flexible displacement sensor with a long stroke. Figure 4 shows the relation between supply pressure and the generated force of the actuator. The upper figure in Fig.4 shows the experimental setup for measuring the generated force. In Fig.4, each symbol shows the number of measurement. In the experiment, under the condition when supply pressure of 400 $\mathrm{kPa}$ is applied, the generated pulling force is measured by decreasing supply pressure. The pushing force of the actuator while being pressurized is small because of its flexibility. However, the pulling force in case of decompression is large. The pulling force is an elastic force of the rubber tube in the actuator. The maximum pulling force is approximately $40 \mathrm{~N}$. The generated force characteristics of the actuator also has hysteresis. It is also caused by the friction mentioned above.

\section{Flexible Robot Arm}

As a rehabilitation device with a wider moving area, a flexible robot arm using tested actuators as shown in Fig. 5 is proposed and tested. The robot arm consists of three extension-type actuators with an original length of $200 \mathrm{~mm}$. This length of the actuator is decided by the maximum stretched length of $470 \mathrm{~mm}$ based on the shoulder width. In order to drive both hands for every directions, they are arranged every $120 \mathrm{deg}$. at $30 \mathrm{~mm}$ from the center of the device. Both ends of the actuator are fixed with a triangleshaped plastic plate. The device has 40 thin plates with a width of $1 \mathrm{~mm}$ to keep a parallel arrangement of the three actuators and to increase the bending stiffness of the robot arm. The robot arm has a length, width, and height of $230 \mathrm{~mm}, 90 \mathrm{~mm}$, and $90 \mathrm{~mm}$, respectively. The mass of the arm is $420 \mathrm{~g}$.

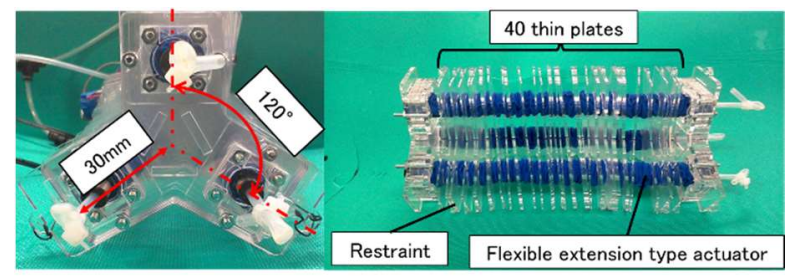

Fig. 5 Overview of movement of flexible robot arm

Figure 6 shows the movement of the arm when some actuators are pressured. From Fig. 6, we can observe that the robot arm can bend in any direction by decompressing one or two of the three actuators.
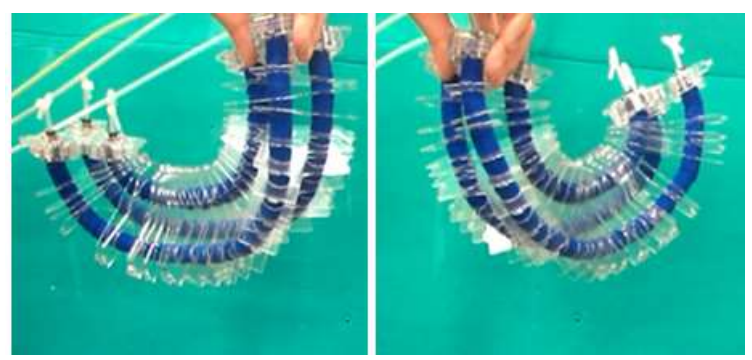

Fig. 6 Appearance of movement of flexible robot arm

To design and control the robot arm, an analytical model that can predict the characteristics of the robot arm is required. Figure 7 shows the analytical model of the flexible robot $\operatorname{arm}^{14)}$. As shown in Figs. 7(b) and (c), the extension-type soft actuator located on the $\mathrm{X}$ axis is defined as actuator 1, and the other actuators arranged in a counterclockwise direction from the position of actuator 1 are defined as actuator 2 and 3. $L_{1}$, $L_{2}$, and $L_{3}$ are the lengths of actuator 1, 2, and 3, respectively. From the geometric relationship as shown in Figs. 7(b) and (c), the following equations can be obtained:

$$
\begin{gathered}
L_{1}=(R-r \cdot \cos \alpha) \cdot \beta, \\
L_{2}=\left\{R-r \cdot \cos \left(\frac{2 \pi}{3} \alpha\right)\right\} \cdot \beta, \\
L_{3}=\left\{R-r \cdot \cos \left(\frac{4 \pi}{3}-\alpha\right)\right\} \cdot \beta, \\
R=\frac{L}{\beta},
\end{gathered}
$$

where $L$ is the central length of the robot arm, $R$ is the radius of curvature of the arm, and $r$, which is $30 \mathrm{~mm}$, is the distance between the center of the arm and the center of each actuator. $\alpha$ and $\beta$ are the bending direction angle and bending angle, respectively. By using Eqs. (1) to (4), the central length of the robot $\operatorname{arm} L$, bending directional angle $\alpha$, and bending angle $\beta$ can be expressed as follows:

$$
L=\frac{L_{1}+L_{2}+L_{3}}{3} \text {, }
$$

$$
\alpha=\tan ^{-1} \frac{\sqrt{3}\left(L_{3}-L_{2}\right)}{L_{2}+L_{3}-2 L_{1}},
$$




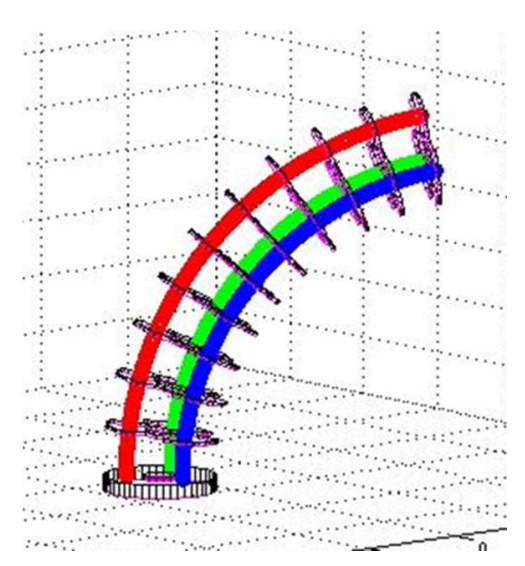

(a) Overview of analytical model of robot arm

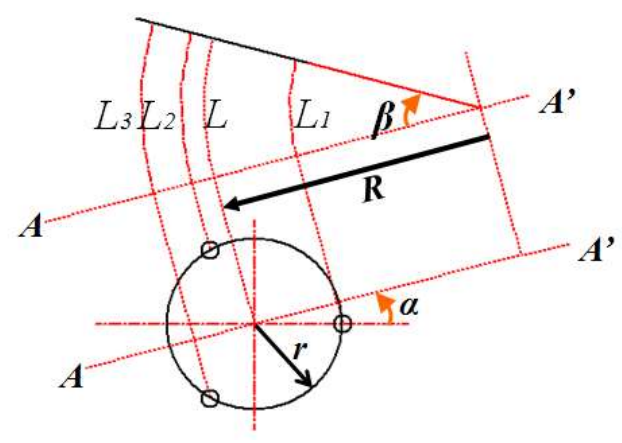

(b) Definition of lengths of each actuator

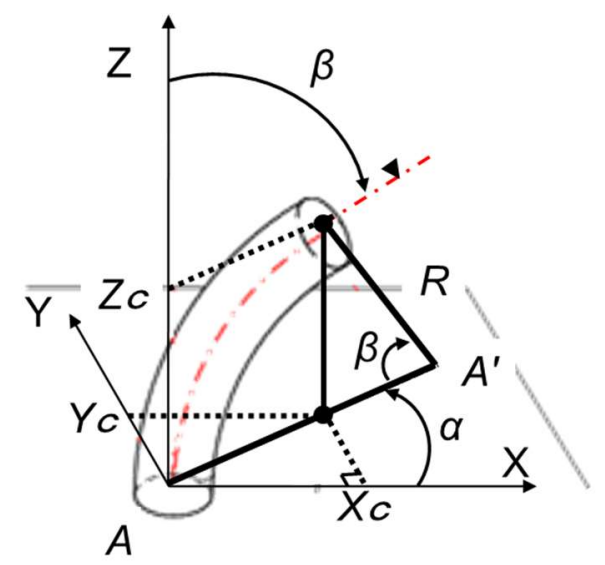

(c) Definition of angles $\alpha$ and $\beta$

Fig. 7 Analytical model of robot arm

$$
\beta=\frac{L-L_{1}}{r \cdot \cos \alpha}
$$

When $\cos \alpha=0$, the bending angle $\beta$ can be obtained by the following equation from Eqs. (2) and (3):

$$
\beta=\frac{\left|L_{3}-L_{2}\right|}{\sqrt{3} r} .
$$

From Eqs. (4) and (7), the radius of curvature of the $\operatorname{arm} R$ is given by

$$
R=\frac{L \cdot r \cdot \cos \alpha}{L-L_{1}}
$$

When each actuator is pressurized, each length of the actuator $L_{i}$ is given by

$$
L_{i}=L_{0 i}+\frac{A\left(P_{i}-P_{\min }\right)}{k} .
$$

where $L_{0 i}, P_{i}, P_{\min }, k$, and $A$ are the initial length of each actuator, the supply pressure, minimum supply pressure (160 $\mathrm{kPa}$ ), elastic coefficient, and the sectional area of the tube in the actuator, respectively.

Next, the calculated posture of the arm using the model was compared with the experimental one. Figure 8 shows a comparison of the arm shape when the following pressure was given to each actuator. The supply pressures $P_{1}, P_{2}$, and $P_{3}$ were $200 \mathrm{kPa}, 400 \mathrm{kPa}$, and $400 \mathrm{kPa}$, respectively. Figures 8 (a) and (b) show the experimental result and the calculated result, respectively. From Fig. 8, it can be seen that a bending angle $\beta$ of $70 \mathrm{deg}$. agrees with the experimental result when the elastic coefficient $k$ is $345 \mathrm{~N} / \mathrm{m}$.

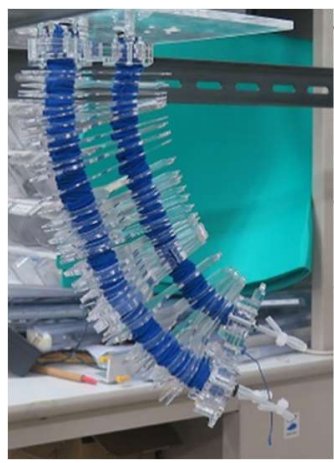

(a) Experimental result

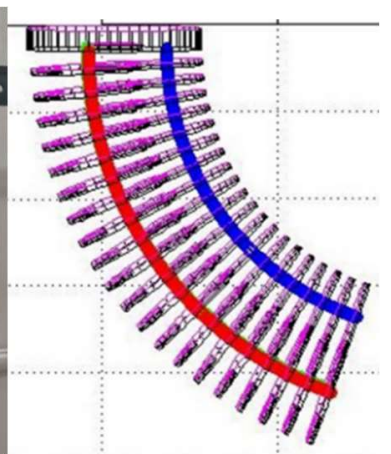

(b) Calculated result
Fig. 8 Comparison of posture of robot arm

Figure 9 shows the relation between the differential pressure and the bending angle of the arm. In the experiment, two types of robot arm that the actuators are set on the location with distance of 30 and $60 \mathrm{~mm}$ form the center of robot arm. The differential pressure means the pressure difference between $P_{1}$ and $P_{2}$ or $P_{3}$. The symbols indicate the experimental results, and the lines indicate the calculated results based on the model. From Fig. 9, it is found that the calculated result does not agree with the experimental result 
when the differential pressure is higher than $250 \mathrm{kPa}$; this is because the elastic coefficient $k$ changes with the supply pressure, as shown in Fig. 3.

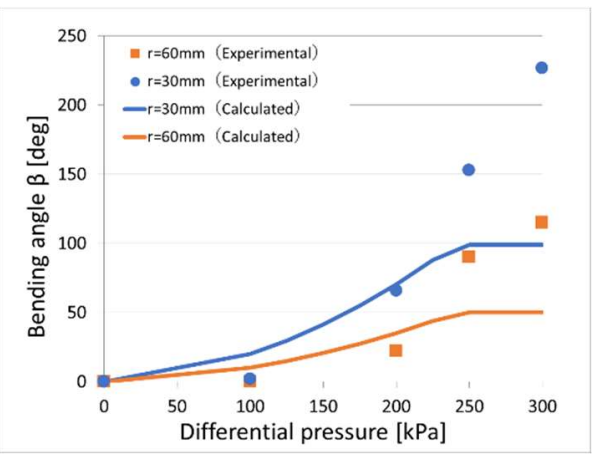

Fig. 9 Relation between differential pressure and bending angle of the robot arm

Figure 10 shows the relation between supply pressure and generated force of the robot arm at the point of arm end. The generated force is measured by the force sensor (AIKOH ENGINEERING Co. Ltd., RX-10) so that the shape of the robot arm can be changed straight by pulling force. As same as the experiment of bending angle, two types of robot arm are used. From Fig.10, it can be seen that the maximum generated force of the robot is about $6 \mathrm{~N}$. We think that it is enough to change the position of hands while both hands hold both ends of the arm. However, it seems that it is not enough to drive whole upper limb. It is necessary to improve the generated force and bending stiffness of the arm as future work.

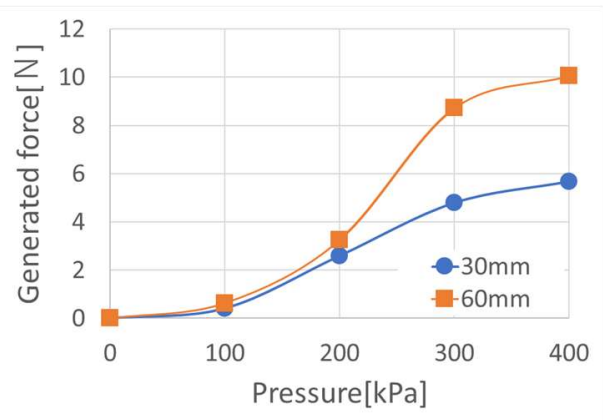

Fig. 10 Relation between supply pressure and generated force of the robot arm at the point of the arm end

\section{Quasi-Servo Valve with Embedded Controller}

Figures 11 and 12 show the construction and a schematic diagram of the quasi-servo valve. The valve consists of two standard on/off-type control valves and an embedded controller. The output port of the first valve is connected to the input port of the second valve. The first valve is a threeport valve that can change the direction of fluid flow from the supply port to the output port, or the fluid flow from the output port to the exhaust port; we call this a "switching valve." The second valve is a two-port valve driven by pulse width modulation (PWM) in order to adjust the valve opening with time.

The PWM valve can adjust the output flow rate, similar to a variable fluid resistance. To decrease the size and cost of the valve, a smaller on/off control valve (SMC Co. Ltd., S070CSDG-32) was used. The price of the new valve ( USD 17) is approximately half that of the previous on/off control valve ${ }^{15)}$. The maximum flow rate of the valve is $8.5 \mathrm{~L} / \mathrm{min}$ when a supply pressure of $400 \mathrm{kPa}$ is applied. This value of the flow rate is sufficient to drive the extension-type soft actuator. As shown in Fig. 11, to realize the compact construction of a connector between two on/off valves, acrylic flow passages were used. The size of the valve without a typical tube connector is $36 \times 25 \times 17 \mathrm{~mm}$. The mass of the valve is only $24 \mathrm{~g}$.

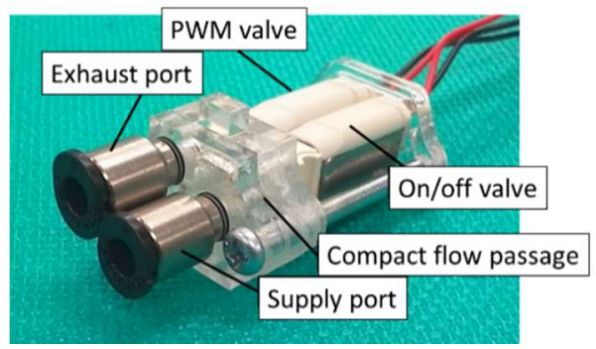

Fig. 11 Construction of quasi-servo valve

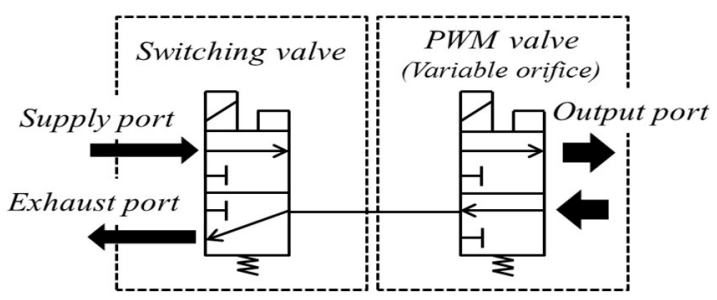

Fig. 12 Schematic diagram of quasi-servo valve

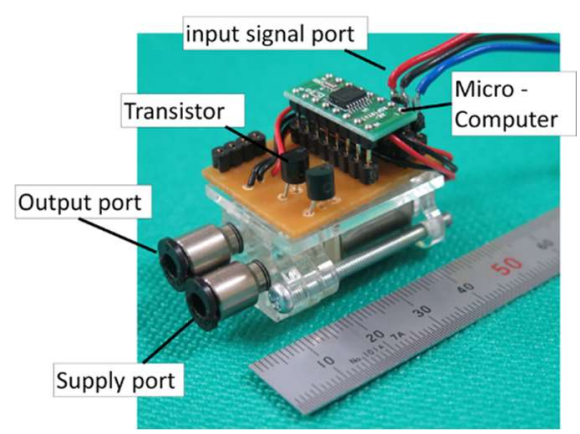

Fig. 13 Construction of tested flow rate control-type quasi-servo valve with built-in driving circuit 
Figures 13 and 14 show the construction and a schematic diagram of a tested flow rate control-type quasi-servo valve with a built-in driving circuit. The driving circuit consists of a tiny embedded controller (Renesas Co. Ltd., RL78/G10) and two transistors (Fairchild Semiconductor Co. Ltd., TO-92 2N7000).

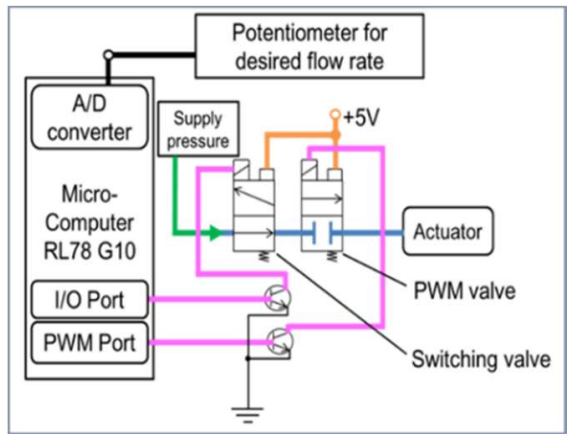

Fig. 14 Schematic diagram of tested flow rate control-type quasiservo valve with built-in driving circuit

The flow rate is controlled as follows: First, the embedded controller obtains an analog signal through the analog to digital(A/D) converter on the embedded controller. In the embedded controller, the input duty ratio is calculated based on an empirical formula ${ }^{10)}$. The required input duty ratio is set through the PWM port of the controller.

Figure 15 shows the relation between the valve opening and the output flow rate of the tested valve. In an experiment, to measure the output flow rate based on the empirical formula ${ }^{10}$ and to observe control parameters such as the input normalized flow rate and output duty ratio, an embedded controller (Renesas Co. Ltd., SH7125) having several serial communication ports was used. From the result shown in Fig. 15 , the valve opening and output flow rate has a linear relationship. This means that the tested flow rate control-type quasi-servo valve can change the sectional area of the valve linearly according to the control input.

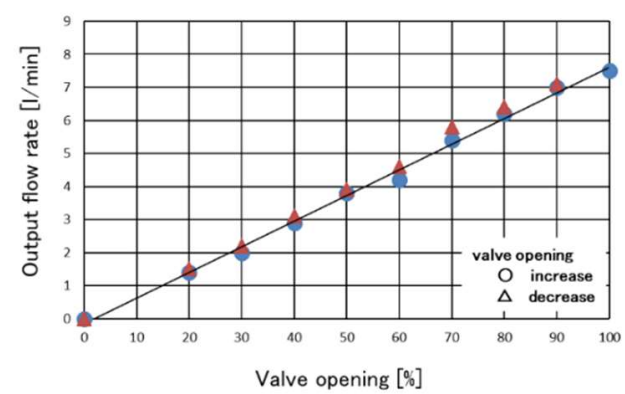

Fig. 15 Relation between valve opening and output flow rate of the tested valve

\section{Portable Rehabilitation Device}

Figure 16 shows an overview of the portable rehabilitation device. The system of the device consists of the tested robot arm, three quasi-servo valves with a built-in embedded controller, three wire-type linear potentiometers ${ }^{13)}$, and a microcomputer (Renesas Co. Ltd., SH7125) to control the rehabilitation device. The tested potentiometer can be disposable, because its material cost is less than 9 US dollars. Even if the actuator bends, the sensor can measure the displacement of the actuator because the wire can move along the shape of the actuator through holes in thin plates. This sensor can also measure a long stroke of $210 \mathrm{~mm}$.

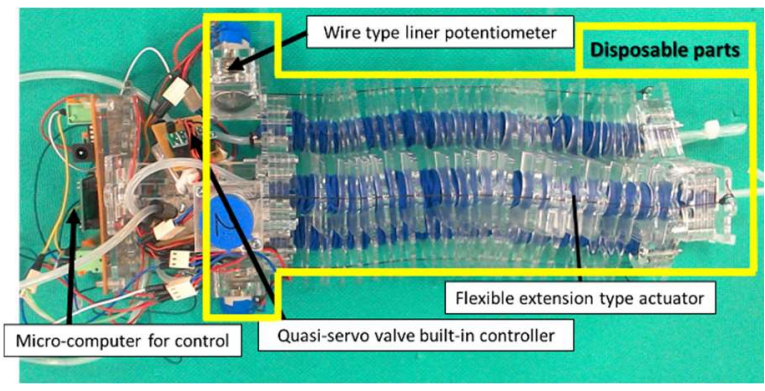

Fig. 16 Overview of portable rehabilitation device

Figure 17 shows a schematic diagram of the portable rehabilitation device. The position control of each actuator in the device is accomplished as follows. First, the wire-type linear potentiometers measure each displacement of the actuators. The output value is taken by the A/D converter in the microcomputer. The error between the desired and measured displacement is calculated by the embedded controller for control.

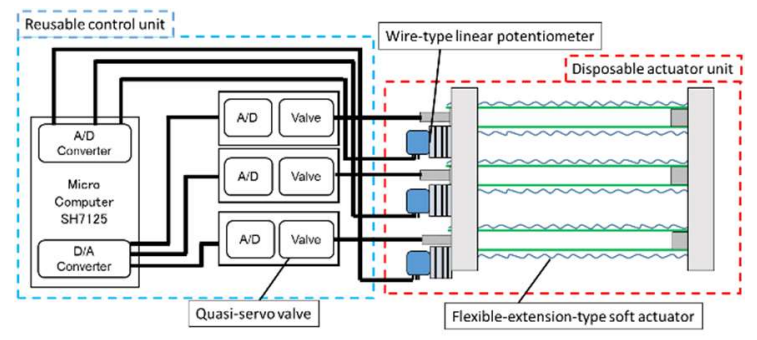

Fig. 17 Schematic diagram of portable rehabilitation device

The control input for the quasi-servo valve is also calculated based on a simple control scheme. The control input for each valve is given as an analog signal from 0 to $5 \mathrm{~V}$ through a digital to analog (D/A) converter with an Serial peripheral interface (SPI) controller (Linear Technology Co. Ltd., LTC1660CN). In the quasi-servo valve, the built-in 
controller can control the valve opening (output flow rate) according to the input voltage based on the empirical formula as shown in Fig. 15.

When the input voltage for the valve is higher than $2.5 \mathrm{~V}$, the valve works as a supply valve. On the other hand, for an input voltage lower than $2.5 \mathrm{~V}$, the valve works as an exhaust valve. For an input voltage of $2.5 \mathrm{~V}$, the valve is closed. The valve opening is controlled according to the absolute value, from $2.5 \mathrm{~V}$, and the attitude of the device is controlled by this method. In the experiment, a reference displacement of 200 $\mathrm{mm}$ is given for each actuator. Then, the target value of 50 $\mathrm{mm}$ for the actuator is changed every $10 \mathrm{~s}$.

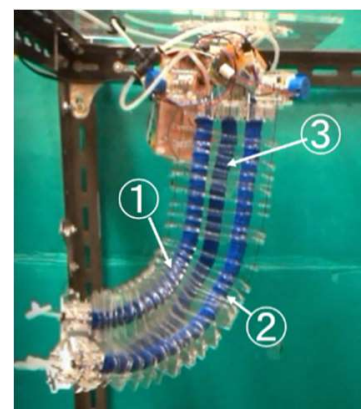

(a) Time: $100 \mathrm{~s}$

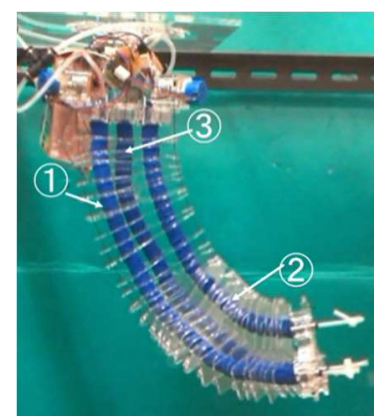

(b) Time: $180 \mathrm{~s}$

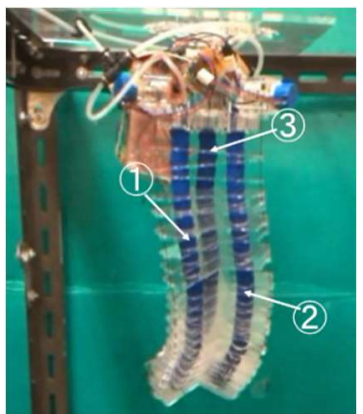

(c) Time: $260 \mathrm{~s}$

Fig. 18 View of attitude control of device

Figure 18 shows a view of the attitude control for the portable rehabilitation device. Figure 19 shows the transient response of the displacement of the actuator. In Fig. 19, the red line and blue line indicate the controlled displacement of the actuator and reference, respectively. It can be found that the controlled displacement agrees with the reference value. This indicates that the device can achieve the target attitude well. In future work, we are going to apply the tested device as a rehabilitation device that can provide passive motion to patients such as an active bender and expander.

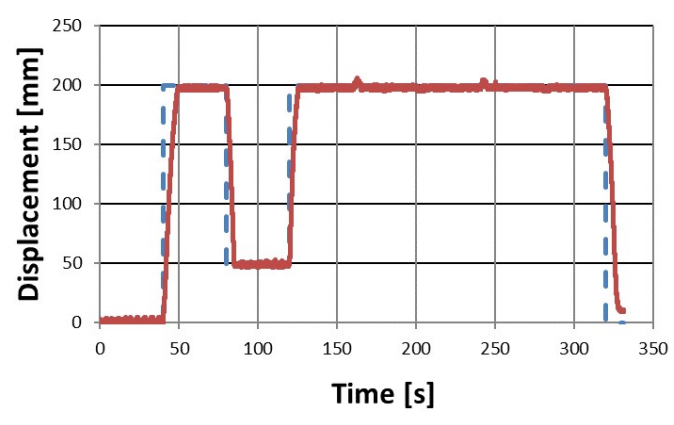

(a) Actuator 1

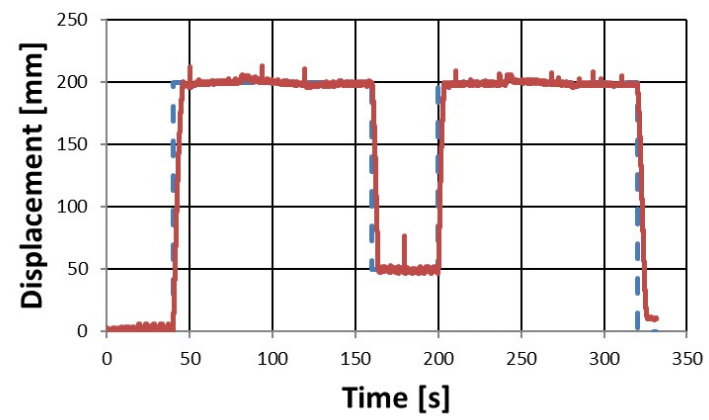

(b) Actuator 2

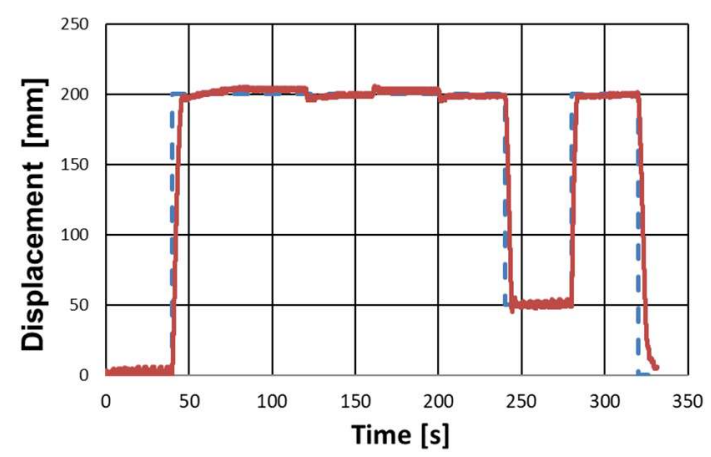

(c) Actuator 3

Fig. 19 Result of attitude control of portable rehabilitation device

\section{Conclusions}

As a low-cost rehabilitation device with a larger moving area, a wrist portable rehabilitation device that has the disposable actuator unit is proposed and tested. As an actuator, a low-cost extension-type soft actuator that can be easily constructed by using the water supply tube on the market is proposed and tested. As a result, we confirm that the tested actuator can extend to more than $200 \%$ of its original length and generate about $40 \mathrm{~N}$, even if the material cost of actuator with $200 \mathrm{~mm}$ length is about 2 US dollars. A flexible robot arm using low-cost actuators and disposable wire-type liner potentiometers is proposed and tested. In addition, to design and control the robot arm, an analytical model of the robot is proposed. We confirm that the calculated result agrees relatively well with the experimental 
result when the supply pressure is low. The difference is caused by the fact that the elastic coefficient changes according to the supply pressure. As a reusable control unit, a flow rate control-type quasi-servo valve with a built-in an embedded controller and the attitude controller are proposed and tested. The attitude control of the whole device that include disposable actuator unit and control unit is carried out. We can confirm that the controlled displacement agrees with the reference.

As future work, we are going to apply the tested device as a rehabilitation device that can provide passive motion to patients such as an active bender and expander.

\section{References}

1) Nagata, Y. ed.: Soft Actuators, Forefront of Development, NTS Ltd., p. 291-335 (2004)

2) Ishii, M., Yamamoto, K. and Hyodo, K.: Stand-Alone Wearable Power Assist Suit, Development and Availability, Journal of Robotics and Mechatronics, Vol. 17, p. $575-583$ (2005)

3) Noritsugu, T., Takaiwa, M. and Sasaki, D.: Development of Power Assist Wear Using Pneumatic Rubber Artificial Muscles, Journal of Robotics and Mechatronics, Vol. 21, p. 607-613 (2009)

4) Kobayashi, H., Shiban, T. and Ishida, Y.: Realization of all 7 motions for the upper limb by a muscle suit, Journal of Robotics and Mechatronics, Vol. 16, p. 504-512 (2004)

5) Shimooka, S., Dohta, S., Akagi, T., Moriwake, Y. and Zhao, F.: Estimation of Pressure Control Performance in Low-Cost Quasi-Servo Valve Using Embedded Controller, Lecture Notes in Electrical Engineering 293, Volume 1, Springer, p. 359-366 (2014)

6) Shimooka, S., Dohta, S., Akagi, T. and Moriwake, Y.: Analysis and Simulation of Small-Sized Quasi-Servo Valve Using Tiny On/Off Control Valve, Lecture Notes in Electrical Engineering 345, Springer, p. 59-66 (2015)

7) Matsui, Y., Akagi, T., Dohta. S., Aliff, M. and Liu, C.: Development of Portable Rehabilitation Device Using Flexible Spherical Actuator and Embedded Controller, Lecture Notes in Electrical Engineering 293, Volume 1, Springer, p. 231-238 (2014)

8) Noritsugu, T.: Pneumatic Soft Actuator for Human Assist Technology, Proceedings of the 6th JFPS International Symposium on Fluid Power, p. 11-20 (2005)
9) Elliot W. Hawkes, David L. Christensen, Allison M. Okamura: Design and implementation of a $300 \%$ strain soft artificial muscle, 2016 IEEE International Conference on Robotics and Automation, p. $4022-4029$ (2016)

10) Yoneda, M., Akagi, T., Dohta, S., Kobayashi, W., Moriwake, Y. and Zhao, F.: Development of Flow Rate Control Type Quasi-Servo Valve Using Small-Sized On/Off Valves, 2nd International Conference on Robotics and Automation Sciences, S16 (2016)

11) Shimooka, S., Dohta, S., Akagi, T. and Moriwake, Y.: Position Control of Rubber Artificial Muscle Using Builtin Ultrasonic Sensor and Quasi-Servo Valve, International Journal of Mechanical Engineering and Robotics Research, Vol. 4, No. 4, p. 304-308 (2015)

12) Matsui, Y., Akagi, T. and Dohta. S.: Development of Flexible Displacement Measuring System Using WireType Linear Encoder for Flexible Spherical Actuator, Procedia Computer Science, Vol. 76, p. 113-118 (2015)

13) Matsui, Y., Akagi, T. and Dohta, S.: Development of Low-Cost Wire Type Linear Potentiometer for Flexible Spherical Actuator, Proceedings of 2016 IEEE International Conference on Advanced Intelligent Mechatronics AIM2016, 16340660 (2016)

14) Aliff, M., Akagi, T. and Dohta, S.: Trajectory Control of Robot Arm Using Flexible Pneumatic Cylinders and Embedded Controller, Proceedings of 2015 IEEE/ASME International Conference on Advanced Intelligent Mechatronics, p. 1120-1125 (2015)

15) Zhao, F., Akagi, T. and Dohta, S.: Development of SmallSized Quasi-Servo Valve for Flexible Bending Actuator, Proceedings of 2009 CACS International Automatic Control Conference, p. 558-562 (2009) 